\section{Parasitic infection of Heterakidae family in a Rosy Pelican}

I. Lourderaj ${ }^{1}$, M. Mohan ${ }^{1,2}$ and K. Coumarane ${ }^{1}$

1,2 Veterinary Assistant Surgeons, Veterinary Dispensary, Puducherry 605001, India

Email: ${ }^{2}$ mohanpsp@yahoo.co.in (corresponding author)

plus web supplement of 1 page

Two Rosy Pelicans aged about nine months weighing $2.5 \mathrm{~kg}$ and $3 \mathrm{~kg}$, respectively were reared at the Department of Forests and Wildlife, Puducherry. As a general health checkup two pelicans were examined for endoparasitic infection. Fresh faecal droppings were collected from them during the month of October 2006. Standard parasitologic techniques for examination of faecal droppings were done as per the method described by Soulsby (1982). Both the direct smear and centrifugal floatation technique revealed the presence of parasitic eggs. Of the two pelicans examined, one of them had harboured parasitic egg. The morphology of the egg was unique to the egg of parasite belonging to the family Heterakidae. The egg was oval with smooth shell and unsegmented in nature (Image $1^{w}$ ). Because a specific diagnosis cannot always be made from the eggs it may be necessary to cultivate the larvae from those eggs that hatch in free state (Soulsby, 1982). Hence, the parasitic infection is identified up to the family level Heterakidae. But the morphology of the egg was comparable with either Heterakis sp or Ascaridia sp. Soulsby (1982) stated that the family Heterakidae consists of parasites like Heterakis sp and Ascaridia sp etc., which can infect water birds.

However, Dyer et al. (2002) reported nematodes like Contracaecum sp, Eustrongylides sp, Syngamus sp, Tetrameres sp, Physaloptera sp, Paracuaria sp in Brown Pelican. Perusal of literature revealed that studies on endoparasitic infection of pelicans in India are scanty. An ascarid, Contracaecum sp was reported in the Brown Pelican Pelecanus occidentalis (Grimes et al., 1989; Greve et al., 1986).

\section{References}

Dyer, W.G., E.H. Williams Jr, A.A. Mignucci-Giannoni, N.M. JimenezMarrero, L. Bunkley-Williams, D.P. Moore \& D.B. Pence (2002). Helminth and arthropod parasites of the Brown Pelican, Pelecanus occidentalis in Puerto Rico, with a compilation of all metazoan parasites reported from this host in the Western Hemisphere. Avian Pathology 31: 441-445.

Greve, J.H., H.F. Albers, B. Suto \& J. Grimes (1986). Pathology of gastrointestinal helminthiasis in the brown pelican (Pelecanus occidentalis). Avian Diseases 30(3): 482-487.

Grimes, J., B. Suto, J.H, Greve \& H.F. Albers (1989). Effect of selected anthelmintics on three common helminthes in the brown pelican (Pelecanus occidentalis). Journal of Wildlife Diseases 25(1): 139-142.

Soulsby, E.J.L. (1982). Helminths, Arthropods and Protozoa of Domesticated Animals. $7^{\text {th }}$ edition. The Williams and Wilkins Company, Baltimore.

Acknowledgements: We wish to thank Dr. P. Devaraj, IFS, Deputy Conservator of Forests, Department of Forests and Wildlife, Puducherry and Dr. M.C. Rajamanickam, The Director, Department of Animal Husbandry and Animal Welfare, Puducherry for providing all the facilities for conducting this work. The authors are also thankful to Dr. R. Sreekrishnan, Assistant Professor for his kind help.

${ }^{\mathrm{w}}$ See Image $1^{\mathrm{w}}$ in the websupplement at www.zoosprint.org

\section{Treatment of an injured Indian Cobra Naja naja}

T.K. Pattnaik ${ }^{1}$, I. Nath ${ }^{2}$, V.S.C. Bose ${ }^{3}$, P.S. Parbathamma ${ }^{4}$, J.K. Das ${ }^{5}$ and S.S. Lenka ${ }^{6}$

${ }_{1,2}$ Associate Professor, ${ }^{3}$ Professor, ${ }^{4}$ Ph.D scholar, ${ }^{5}$ Assistant Professor, ${ }^{6}$ U.G. scholar, Department of Surgery, Orissa Veterinary College, Bhubaneswar, Orissa 751003, India

Email: ${ }^{2}$ indravet@yahoo.co.in

plus web supplement of 1 page

A bicellate Indian cobra Naja naja was presented by Snake Helpline, an NGO working for the conservation of snakes, with the history that the snake was moving sluggishly with bleeding from its mouth near village Chandrasekharpur outskirts of Bhubaneswar city. The local people informed the NGO who brought it to Veterinary College. The cobra was anaesthetized with $60 \mathrm{mg}$ of ketamine hydrochloride administered intramuscularly. The cobra weighted to be $3.1 \mathrm{~kg}$. After 5 min its mouth cavity was opened which revealed both of its fangs absent with deep wounds (Image $1^{w}$ ). The skin and muscles were partly separated from left side of lower jaw and hanging down. A dorso-ventral radiograph was taken which showed unilateral mandible fracture with multiple fragments (Image $2^{w}$ ). The wounds were cleaned with sterile gauze (Image $3^{\mathrm{w}}$ ) and dressed with $5 \%$ povidone-iodine lotion. Post-operatively gentamycin $50 \mathrm{mg}$ was injected intramuscularly once daily for three days. Fifty $\mathrm{ml}$ of $5 \%$ DNS was administered into the stomach using an infusion set pipe lubricated with xylocaine $2 \%$ jelly (Image $4{ }^{w}$ ). Tube feeding was continued once daily for five days with dressing of the wounds. The snake became active by the sixth day and started moving. Glucose water and milk in separate pans were kept in its enclosure which it took without any difficulty. The Snake Helpline kept it for a month and then released it into nature.

Indian Cobras, being highly poisonous, are likely to be injured by people in panic as happened in this case. Ketamine hydrochloride at the dose rate of $20 \mathrm{mg} / \mathrm{kg}$ body weight was injected intramuscularly for dressing of intra-oral wounds with slight mobility which prompted us to use xylocaine jelly for lubricating the feeding tube. The similar dose rate was recommended by Glenn et al., 1972 for tranquilizing snakes around $2 \mathrm{~kg}$ with slight mobility. Since there were multiple fragments no attempt for fracture repair was undertaken. Tube feeding and dressing of the wounds helped in the recovery of the snake

\section{Reference}

Glenn, J.L, R. Straight \& C.C. Snyder (1972). Clinical use of ketamine hydrochloride as an anesthetic agent for snakes. American Journal of Veterinary Research 33: 1901.

Acknowledgement: Authors are thankful to the Dean, Orissa Veterinary College for according permission to undertake the work.

Editor's Note: Although releasing such snakes could be termed 'humane', this course of action is not recommended due to the incapability of the snake to hunt.

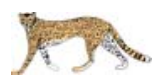

Manuscript 1727; (C ZOO; Date of publication 21 November 2007 Received 27 February 2007; Finally accepted 30 September 2007
${ }^{w}$ See Images $1-4^{w}$ in the websupplement at www.zoosprint.org

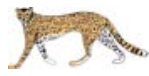

Manuscript 1748; (C) ZOO; Date of publication 21 November 2007 Received 28 March 2007; Revised received 05 October 2007; Finally accepted 15 October 2007 